\title{
O NOVO PAPEL DAS EMPRESAS NA PROTEÇÃO DO MEIO AMBIENTE ${ }^{1}$
}

\author{
THE NEW ROLE OF COMPANIES IN THE ENVIRONMENTAL PROTECTION
}

\author{
Vladimir Passos Freitas ${ }^{2}$
}

\begin{abstract}
RESUMO
O presente artigo tem por objetivo a análise e relevância do compromisso das empresas com a questão ambiental. Na busca deste escopo, foi utilizado o método hipotético-dedutivo, com análise da doutrina, legislação e notícias dos órgãos de comunicação. A pesquisa tem início com a evolução do tema meio ambiente e a desconexão das empresas com a matéria no passado. Na sequência examinam-se as iniciativas tomadas pela Organização das Nações Unidas - ONU para impulsionar o debate, para tanto buscando conectar todos os atores envolvidos. Como resultado da atuação internacional e do agravamento da situação do meio ambiente no mundo, paulatinamente, as corporações foram envolvidas não apenas nos debates ambientais, como também na erradicação da pobreza. A complementar a mudanças na área, os incêndios na Amazônia e os reflexos econômicos negativos que disto decorrem para o Brasil, levaram entes privados a propor mudanças e a pressionar o poder público. Nesta nova realidade, surgem cobranças e propostas junto às empresas, a fim de que assumam um novo protagonismo em relação ao meio ambiente.
\end{abstract}

Palavras-chave: ODSs da ONU; Empresas e meio ambiente; Estímulos à proteção ambiental; Economia e meio ambiente; Amazônia e meio ambiente.

\begin{abstract}
The purpose of this article is to analyze and highlight the companies' commitment to the environmental issue. The hypothetical-deductive method was used, with analysis of the doctrine, legislation, and news from the media. The research begins with the evolution of the subject environment and the disconnection of companies with the topic in the past. Then, initiatives taken by the United Nations - UN to boost the debate are examined, seeking to connect all the actors involved. As a result of international performance and the worsening of the environmental situation in the world, companies have gradually been involved not only in environmental debates, but also in the eradication of poverty. In addition to changes in the area, fires in the Amazon and the consequent negative economic effects for Brazil have led private entities to propose changes and put pressure on the government. In this new reality, companies are faced with demands and proposals to assume a new role regarding the environment.
\end{abstract}

\footnotetext{
${ }^{1}$ Artigo escolhido e aprovado pelo Conselho Editorial. O autor foi convidado especialmente para escrever o presente artigo para este número da Revista DD\&EM.

${ }^{2}$ Pós-doutor pela Universidade de São Paulo. Mestre e Doutor em Direito pela Universidade Federal do Paraná. Professor de Direito Ambiental da graduação e da pós-graduação da Pontifícia Universidade Católica do Paraná. Desembargador Federal, ex-Presidente do Tribunal Regional Federal da 4ª Região. Ex-Secretário Nacional de Justiça.
}

Revista Direitos Democráticos \& Estado Moderno |Faculdade de Direito da PUC-SP https://revistas.pucsp.br/index.php/DDEM | No. $01 \mid$ p.02-16| Jul./Dez. 2020 
Keywords: UN SDGs; Companies and the environment; Incentives for environmental protection; Economy and environment; Amazon and environment.

\section{INTRODUÇÃO}

Os primeiros problemas ambientais em larga escala começaram a surgir no século XVIII, com o processo de industrialização na Inglaterra, na chamada Primeira Revolução Industrial. No século XX surgiram os primeiros Tratados visando proteger bens naturais e paisagísticos, como a Convenção de Londres de 1900, que foi um Tratado Internacional Multilateral, dispondo sobre a criação de parques para a conservação da natureza. Este movimento influenciou a legislação brasileira nos anos 1930, com a edição de vários diplomas como, por exemplo, o primeiro Código Florestal (1934) e a criação de Parques Nacionais, como o de Itatiaia (1937).

Todavia, as primeiras preocupações com a proteção do meio ambiente, de forma coordenada e a nível internacional, tiveram seu início nos anos 1960, através de tímidos encontros internacionais que exteriorizavam a necessidade de proteção da natureza. Eram os reflexos da obra escrita em 1962 por CARSON (2010), "Primavera Silenciosa", autêntico brado de guerra contra o uso indiscriminado de pesticidas. Desta época é o início da criação de movimentos ecológicos preservacionistas e conservacionistas e o relatório "Limites do Crescimento", preparado pelo Clube de Roma, um movimento de intelectuais fundado em 1968 pelo italiano Aurelio Peccei e pelo escocês Alexander King, para estudos de política internacional, economia e meio ambiente.

Fruto destes novos ventos foi a edição, no Brasil, de um novo Código Florestal (Lei 4.771, de 15/09/1965), uma Lei de Proteção à Fauna (Lei 5.197, de 03/01/1967) e o Código de Pesca (Decreto-lei 221, de 28/02/1967).

A chegada dos anos 1970 foi de grandes mudanças. No âmbito acadêmico, em 1971 Eugene P. Odum, diretor do Instituto de Ecologia da Universidade da Geórgia, alertava que:

Quando a população humana de uma dada área é pequena, a má utilização do solo poderá apenas afectar as pessoas que por ela são responsáveis. Porém, à medida que a população aumenta, todos sofrem quando a terra é utilizada inadequadamente, dado que todos pagam eventualmente para a sua reabilitação ou, como costuma agora acontecer, todos sofrem uma perda permanente de recursos. Por exemplo, se as pradarias em regiões de baixa queda pluviométrica forem lavradas e semeadas com trigo (mau uso do solo), mais cedo ou mais tarde o resultado será uma "bacia de pó" ou um deserto temporário. A recuperação é dispendiosa, e todos como contribuintes terão de 
pagar. Caso a cobertura herbácea seja mantida e pastoreada moderadamente (bom uso do solo), não dará aos a que se desenvolva uma bacia de formação de poeira. Semelhantemente, se a falta de restrições locais de zonagem permite a construção de casas e fábricas em planícies sujeitas a inundações (ou poderá este ser evitado apenas através de estruturas de controlo da inundação muito dispendiosas). Se pelo contrário, as planícies inundáveis são utilizadas para recreio, silvicultura ou agricultura (boas utilizações do solo), aos impostos será acrescentado valor e não subtraído. O uso do solo é assim um empreendimento de toda a gente, e a aplicação de princípios ecológicos ao planejamento do uso do solo é, no presente, indubitavelmente a aplicação mais importante da ciência do ambiente. (ODUM, 1988, p. 670).

No entanto, foi a partir da Conferência das Nações Unidas sobre o Meio Ambiente, realizada em Estocolmo, Suécia, entre 5 e 16 de junho de 1972, que a matéria entrou na agenda internacional. Aquele primeiro e grande encontro gerou consequências que se exteriorizaram em todos os Poderes dos Estados. Nas Assembleias e Câmaras do Poder Legislativo, ocasionou seguidas alterações normativas, regra geral, a partir das Constituições. Mas isto foi sendo feito paulatinamente e não de forma abrupta, pois, afinal, tratava-se de tema novo e havia fortes resistências.

Bem por isso, USERA (2004, p. 45) observa que "a introdução nos textos constitucionais europeus de proclamações de direito ao meio ambiente se fez de forma muito cuidadosa. No geral, somente em Constituições de novo perfil, aparecidas a partir dos anos setenta”. No Brasil, da mesma forma, a proteção ambiental teve início de forma cautelosa.

É certo afirmar que o primeiro passo foi dado com o Decreto-Lei 1.413, de 14 de agosto de 1975, que dispõe sobre o controle da poluição do meio ambiente provocada por atividades industriais. O referido diploma foi editado para atender aos reclamos de proteção do meio ambiente por parte da comunidade internacional. O Brasil passava por processo de forte industrialização, com problemas de poluição em algumas cidades, como Cubatão - SP e Volta Redonda - RJ. Afirmava o art. $1^{\circ}$ que "as indústrias instaladas ou a se instalarem em território nacional são obrigadas a promover as medidas necessárias a prevenir ou corrigir os inconvenientes e prejuízos da poluição e da contaminação do meio ambiente".

Ao Decreto-Lei citado seguiram-se leis tratando de pontos diversos na área ambiental. Especial registro merecem, pelo pioneirismo e pela clareza da redação, a Lei 6.938, de 31 de agosto de 1981, que criou a Política Nacional de Meio Ambiente, e a Lei 7.437, de 15 de julho de 1985, que dispôs sobre a ação civil pública para apurar a responsabilidade civil por danos coletivos causados ao meio ambiente. 
A Constituição, no artigo 225 "caput" e em outros esparsos no seu texto, aumentou o leque de proteção ambiental, sendo que depois leis complementaram a norma constitucional. Assim, por exemplo, a Lei 9.605, de 12 de fevereiro de 1998, deu o necessário reforço penal. A Lei 9.985, de 18 de julho de 2000, criou o Sistema Nacional de Unidades de Conservação da Natureza (SNUC). A estes dois diplomas legais outros tantos se seguiram, à medida que se revelavam as necessidades.

Agora, passados quase 50 anos da histórica Conferência de Estocolmo, a questão ambiental tornou-se uma preocupação mundial que ultrapassa fronteiras, regime político, origem étnica e religiosa dos países. Os efeitos e as consequências do aquecimento global, para ficar no exemplo mais eloquente, colocam em posição de igualdade continentes desenvolvidos e em desenvolvimento. O problema que já se faz sentir os une.

Por outro lado, o desenvolvimento econômico, que a todos sensibiliza e do qual depende a paz social, não pode mais seguir isolado, mas sim alinhar-se com a proteção do meio ambiente. Como bem alerta MACHADO (2014, p. 860):

(...) a integração meio ambiente e desenvolvimento não é um favor ao meio ambiente. Alguns políticos e empresários, e até meios de comunicação, em numerosos países, entendem que se devem reservar somente as migalhas ou as sobras para o meio ambiente, não enxergando que, agindo contra a natureza, o fracasso do empreendimento se não é imediato, virá a médio ou longo prazo.

Diante deste quadro, propõe-se este artigo a procurar estabelecer limites entre estes anseios que, por caminhos diferentes, devem procurar um fim comum.

\section{O DESCOMPROMISSO AMBIENTAL DAS EMPRESAS NO PASSADO}

As empresas no Brasil, inclusive nos anos que deram início ao surgimento das preocupações ambientais, não registravam maior preocupação com a questão ambiental, sob o foco de recursos naturais. Evidentemente, cumpriam normas trabalhistas que vinculavam a proteção do trabalhador a algum aspecto do local onde trabalhava, no que hoje chamamos de meio ambiente do trabalho. Por exemplo, a redação do revogado artigo 168 da Consolidação das Leis do Trabalho, que dispunha: "Deverá ser evitada, tanto quanto possível, na atmosfera dos locais de trabalho, a existência de suspensoides tóxicos, alergênicos, irritantes ou incômodos para o trabalhador". 
Mas isto não significava qualquer predisposição de parceria em um projeto maior. Na verdade, o objetivo das empresas sempre foi o do lucro aos seus sócios ou acionistas, a depender de sua formação estatutária.

Rubens Requião (1975, p. 41) é claro ao mencionar que a empresa se apresenta como "uma combinação de elementos pessoais e reais, colocados em função de um resultado econômico". Fábio Bellote Gomes (2007, p. 7) é mais explícito, ao mencionar que "a busca do lucro é ínsita à atividade empresarial, ainda que, muitas vezes, ele não se verifique efetivamente, visto que o empresário pode ter prejuízos".

Ora, se a meta de uma pessoa jurídica era apenas o resultado econômico, dela, tradicionalmente, não se esperava mais do que o cumprimento das normas ambientais que lhe eram impostas. Consequentemente, qualquer ato que extrapolasse tal conduta, no âmbito social ou ambiental, só poderia ser visto e avaliado como um gesto de magnanimidade.

No entanto, mudanças culturais, sociais e ambientais fizeram com que esta posição tradicional fosse sofrendo mudanças ao longo do tempo. Fruto, inclusive, da mudança de paradigmas do sistema capitalista, que chegou à proposta de estabelecimento do chamado Capitalismo Humanístico, que visa a um desenvolvimento fraterno, com redução da exclusão social e respeito ao princípio da dignidade humana (SAYEG; BALERA, 2011).

\section{A MUDANÇA A PARTIR DA ORGANIZAÇÃO DAS NAÇÕES UNIDAS - ONU}

A sempre lembrada Conferência da ONU em Estocolmo, realizada em 1972, gerou tímidas referências ao meio ambiente. Genéricas referências foram feitas nos Princípios 12 e 13 da Conferência, formulados no futuro do pretérito ("recursos deveriam" ou "os Estados deveriam adotar...") e com foco restrito.

Todavia, vinte anos depois, em Conferência realizada no Rio de Janeiro (1992), as discussões sobre o tema ganharam corpo e a conclusão foi mais enfática. Estabeleceu o Princípio 4, que:

4. Para alcançar o desenvolvimento sustentável, a proteção ambiental deve constituir parte integrante do processo de desenvolvimento, e não pode ser considerada isoladamente deste.

No ano de 2000, a Organização das Nações Unidas deu um passo importante na consecução de tal objetivo. Por iniciativa do seu então secretário-geral, Kofi Annan, foi criado

Revista Direitos Democráticos \& Estado Moderno |Faculdade de Direito da PUC-SP https://revistas.pucsp.br/index.php/DDEM | No. 01 | p.02-16| Jul./Dez. 2020 
o Pacto Global, que é uma convocação para as empresas aderirem a 10 princípios universais nas áreas de Direitos Humanos, Trabalho, Meio Ambiente e Anticorrupção. Na área do meio ambiente, foram apontados os seguintes princípios (PACTO GLOBAL, 2000):

a) As empresas devem apoiar uma abordagem preventiva aos desafios ambientais.

b) Desenvolver iniciativas para promover maior responsabilidade ambiental.

c) Incentivar o desenvolvimento e difusão de tecnologias ambientalmente amigáveis.

Consequência destas linhas mestras foi a adoção, na Conferência de Joanesburgo em 2002, conhecida como Rio +10 , de metas que vão além do desenvolvimento e do meio ambiente, incluindo a erradicação da pobreza e o fortalecimento da participação mais efetiva e construtiva do empresariado e das organizações não governamentais nas discussões internacionais sobre desenvolvimento sustentável.

Dez anos depois, na Rio +20 , renovou-se o propósito de erradicação da pobreza e desenvolvimento de uma economia limpa, à qual se deu o nome de economia verde. Na ocasião foi editada a Agenda 21, que é uma proposta de novos métodos de proteção ambiental, erradicação da pobreza e eficiência econômica, mas sem explícitas atribuições às empresas.

Como se vê, a evolução do tema é lenta e sem grandes ousadias, pela simples razão de que a ONU é uma entidade que reúne Estados. Apesar das naturais dificuldades de consenso, geralmente originadas de divergências econômicas ou políticas, é possível que se chegue a um denominador comum. Já nas empresas, a situação é mais difícil. Elas encontram-se no interior dos Estados e o consenso passa por aspectos mais complexos, entre eles o da concorrência.

No entanto, registre-se que a ONU persiste nos objetivos do desenvolvimento sustentável e agora, mais enfaticamente, formula-os através dos chamados ODS, que "são um apelo global à ação para acabar com a pobreza, proteger o meio ambiente e o clima e garantir que as pessoas, em todos os lugares, possam desfrutar de paz e de prosperidade" (NAÇÕES UNIDAS BRASIL).

Os ODSs, em número de 17, surgiram em 2015, devendo ser cumpridos até 2030. Além dos propósitos ambientais já consolidados, enfatiza-se a necessidade de erradicação da pobreza e redução das desigualdades. Evidentemente, cuida-se de projeto ambicioso e que necessita de um esforço conjunto que permita a inclusão de todos em uma realidade que ofereça as mínimas condições de uma existência digna. No entanto, como alertam Pozzoli e Toledo (2017, p. 179):

Uma grande dificuldade encontrada quando o tema é a dignidade humana, trata-se da sua efetividade. É possível a aplicação deste princípio uma vez que podemos analisar cada ato do universo jurídico com uma carga de valores 
próprios de uma sociedade ou de uma parcela desta sociedade, baseando-as nas condutas morais e éticas de cada sociedade que são possíveis de serem encontradas na mera compreensão das práticas sociais.

Nesta linha, o ODS 17 estabeleceu ser necessário "Fortalecer os meios de implementação e revitalizar a parceria global para o desenvolvimento sustentável". Dividido em diversos itens, no denominado Parcerias Multisetoriais convoca os países aderentes a:

17. Incentivar e promover parcerias públicas, público-privadas e com a sociedade civil eficazes, a partir da experiência das estratégias de mobilização de recursos dessas parcerias.

Como se vê, aí está o fundamento jurídico para a convocação das empresas para aderir ao pacto global de sustentabilidade. Ainda que timidamente, há recomendação expressa à criação de incentivos e promoção de parcerias público-privadas, ou seja, ação conjunta entre os Estados e as empresas.

Por fim, merece ser lembrado ainda que as Declarações da ONU alavancam a legislação doméstica dos países envolvidos. Por exemplo, a Emenda Constitucional 42, de 19/12/2003, deu nova redação ao artigo 170 da Constituição brasileira que, no seu inciso VI, condiciona o desenvolvimento à defesa do meio ambiente. Não por coincidência, no ano seguinte à Rio +10 .

Este adendo à Carta Magna gerou efeitos no mundo real. O Supremo Tribunal Federal, por meio de antiga decisão de $1^{\circ}$ de setembro de 2005, em Medida Cautelar apresentada em Ação Direta de Inconstitucionalidade relatada pelo ministro Celso de Mello, teve oportunidade de avaliar o conflito muitas vezes existente entre a preservação do meio ambiente e o desenvolvimento econômico. Assim registra a ementa:

A incolumidade do meio ambiente não pode ser comprometida por interesses empresariais nem ficar dependente de motivações de índole meramente econômica, ainda mais se se tiver presente que a atividade econômica, considerada a disciplina constitucional que a rege, está subordinada, dentre outros princípios gerais, àquele que privilegia a "defesa do meio ambiente" (CF, art. 170, VI), que traduz conceito amplo e abrangente das noções de meio ambiente natural, de meio ambiente cultural, de meio ambiente artificial (espaço urbano) e de meio ambiente laboral. (STF, 2005).

Mas, por óbvio, o suporte que esta decisão judicial da Suprema Corte possa dar a conflitos submetidos ao Poder Judiciário não é, por si só, suficiente para impor mudança radical nas práticas empresariais. 


\section{O LUCRO, A ADMINISTRAÇÃO AMBIENTAL E A REAÇÃO DAS EMPRESAS}

O mundo corporativo persegue o lucro e esta é a essência do capitalismo. Qualquer interferência estatal nesta área não apenas poderá ser considerada inconstitucional, por ofensa ao artigo 170 da Constituição, que adota o princípio da liberdade econômica e da livre iniciativa, como poderá ensejar consequências econômicas indesejáveis.

As empresas, com o objetivo de maior lucro, tentam diminuir os custos dos produtos que oferecem. Todavia, a adesão voluntária a um plano de ampla proteção ambiental poderá significar o surgimento de despesas extraordinárias, por vezes significativas. E a firma concorrente que não aderir e continuar a poluir o solo, o ar ou a água, colocará seus produtos com menor preço no mercado.

A partir desta realidade, fácil é concluir que órgãos ambientais necessitam estar bem estruturados e gozar da eficiência que deles se espera. Se assim não for, empresas conscientes da necessidade da preservação ambiental não se sentirão estimuladas a cooperar.

Aspecto a merecer realce é o da certificação. Conhecido como "selo verde", o reconhecimento por órgãos privados de controle permite a venda do produto em mercados mais exigentes. Nesta linha a ISO, sigla da "International Organization for Standardization", uma federação internacional não vinculada à ONU, com sede em Genebra, Suíça, que no Brasil é representada pela Associação Brasileira de Normas Técnicas - ABNT, edita normas de cumprimento voluntário pelas empresas.

A ISO 14.000 foi a primeira grande mudança. Ela cuida de procedimentos que devem ser adotados para reduzir ao máximo os danos ao meio ambiente. Por exemplo, a água que entra limpa na empresa, dela deve sair nas mesmas condições. Posteriormente foi editada a ISO 14.001:2015, que exige medidas que gerem efeitos também fora da empresa, incluindo boas condições ambientais locais, regionais e globais que afetem a organização ou que possam vir a ser influenciadas por ela.

O chamado "selo verde" é reconhecimento quase obrigatório para a exportação de produtos brasileiros para a Europa e não só para o velho continente. Como já se advertia em 2003 - e agora com maior razão - "Selos distinguindo madeira de empresas florestais certificadas, serão úteis no marketing das empresas do setor madeireiro e papeleiro, as que querem colocar seus produtos nos mercados madeireiros europeus" (BECKER, 2003). Na 
mesma linha, os países árabes, importantes parceiros comerciais na importação da carne, exigem a chamada certificação Halal, ou seja, que esteja conforme as regras estabelecidas pela Lei Islâmica (Shariah).

Porém, este importante reconhecimento tem um aspecto cruel, ou seja, ele atinge o pequeno produtor. Com efeito, a certificação implica em despesas extraordinárias, que afetarão empresas de menor porte, quiçá inviabilizando a produção. É preciso que se ache solução a este problema, pois não é objetivo da nossa Constituição, nem dos ODSs da Organização das Nações Unidas, debilitar empresas de menor porte.

Digna de menção é a Lei 6.404, de 15/12/1976, que dispõe sobre a Sociedade por Ações, a qual, no artigo 154, explicitamente faz referência ao dever do administrador de exercer todas as suas obrigações legais e estatutárias, com o objetivo de alcançar os fins e interesses da companhia, "satisfeitas as exigências do bem público e da função social da empresa". O administrador a que a lei se refere é o acionista controlador, cujos deveres estão descritos no artigo 116 do referido diploma legal.

No entanto, o mesmo não ocorre na questão ambiental, onde são raras as ações voluntárias da iniciativa privada. Provavelmente, porque a legislação já lhes impõe muitas restrições.

Camila Cardoso Lima e Lincoln Rafael Horácio, em estudo apresentado perante encontro do Conselho Nacional de Pesquisa e Pós-Graduação em Direito - CONPEDI, em Curitiba, reportam-se à doutrina de Reinaldo Dias (2011, apud LIMA e HORÁCIO, 2016, p. 20), para registrar diversas medidas que poderiam ser tomadas pelas empresas, a fim de tornarem mais sustentável a gestão ambiental de seus negócios. Assim registra o autor citado no estudo:

- implantar um sistema de gestão ambiental;

- proceder modificações no processo produtivo, substituindo os produtos tóxicos ou nocivos por outros menos prejudiciais;

- estabelecer um programa de redução de emissões poluentes

- estabelecer programas de formação e informação ambiental para o quadro pessoal da organização;

- criar um setor responsável, prioritariamente, com a questão ambiental na organização;

- elaborar códigos de conduta de respeito ao meio ambiente;

- participar ativamente das campanhas educativas e de prevenção organizadas pelos governos em todos os níveis (municipais, estadual e nacional), e daquelas promovidas pelas entidades representativas do seu setor produtivo; - recuperar e reciclar os seus produtos e subprodutos;

- promover e incentivar a pesquisa de novas tecnologias e novos produtos que não prejudiquem o meio ambiente; 
- diminuir o consumo de matérias-primas, água e energia;

- diminuir a produção de resíduos e assegurar um tratamento correto dos mesmos.

Recentemente, entrou na pauta das empresas o chamado compliance, que é a conformidade das empresas não apenas com os dispositivos legais, mas também com o dever ético de comprometer-se com a integridade. Isto significa que não basta cumprir as normas do sistema jurídico, devendo as empresas dar um passo à frente.

É fácil exemplificar. A legislação, em determinados casos, impõe ao produtor que dê destino aos resíduos que produz com o seu negócio, ou seja, a chamada logística reversa. É o caso, por exemplo, dos invólucros que acondicionam agrotóxicos, cuja devolução é obrigatória, por força dos arts. 33, da Lei 12.305, de 02/08/2010, 12-A, inc. I e 15 da Lei 7.802, de 11/07/1989, combinados com art. 84, inc. III, do Decreto 4.074, de 04/01/2002. Ora, se uma empresa que não tem o dever de tratar de seus resíduos tomar a iniciativa de incentivar a sua devolução e encaminhá-los a aterros sanitários, certamente estará praticando uma ação ambientalmente correta e dando efetiva colaboração para a proteção do meio ambiente. E, obviamente, criando uma imagem positiva que terá reflexos nas aquisições pelos consumidores, principalmente pelos mais esclarecidos.

\section{COBRANÇA E ESTÍMULOS PARA O PROTAGONISMO DAS EMPRESAS EM RELAÇÃO AO MEIO AMBIENTE}

Não podemos, todavia, supor ingenuamente que as empresas se submeterão a lucros menores pelo simples prazer de serem consideradas amigas do meio ambiente. Não é esta a lógica do mercado. E se assim é, fácil é concluir que o mundo corporativo pode e deve ser estimulado, induzido mesmo, a atuar de forma mais assertiva na questão ambiental. Nesta linha de pensamento, tudo indica que estamos passando por uma fase de transformação.

Recentes acontecimentos na Amazônia, relacionados com incêndios florestais, geraram na esfera internacional forte reação de países contra a política ambiental adotada pelo Brasil. Aos 18 de setembro de 2019, portanto antes das ocorrências deste ano de 2020, um grupo de 230 investidores institucionais internacionais, com ativos sob gestão de US\$ 16,2 trilhões, subscreveu uma carta contra queimadas e desmatamento na Amazônia (SILVA JUNIOR, 2019). 
No dia 16 de dezembro de 2019, o Fórum Econômico Mundial, realizado em Davos, Suíça, lançou um novo documento adequado à atual realidade, com destaque para as mudanças climáticas, automação e globalização, nele dando forte apoio a um modelo de capitalismo que não vise apenas a resultados para os acionistas das empresas, mas que também persiga objetivos ambientais, sociais e de boa governança (MEIRELES, 2019).

Mas foi em 2020 que os fatos se aceleraram. Os incêndios na região amazônica, aos quais se seguiram os da região do Pantanal, originaram a mais alta fonte de inconformismo com a política ambiental brasileira. Para ficar em apenas um exemplo, o Parlamento Europeu rejeitou o acordo de livre comércio entre a União Europeia e o Mercosul, mencionando no texto original as ações do governo brasileiro na área (VALOR ECONÔMICO, 2020).

Críticas como esta, que foi apenas uma das investidas contra o a forma de o Brasil tratar da matéria, sempre receberam ação reativa do Poder Executivo Federal, exteriorizada em diversas manifestações que sustentavam a existência de escusos interesses políticos e tentativa de minar o agronegócio brasileiro, onde a qualidade e a quantidade da produção geram perda de mercado de concorrentes de países desenvolvidos.

Em que pese a mescla de interesses envolvidos e o mosaico de situações ambientais que envolvem a Amazônia, o fato é que a fuga de investimentos no Brasil suscitou fundado receio no mundo empresarial. Em iniciativa inédita, os três principais bancos brasileiros, Itaú, Bradesco e Santander, uniram-se e submeteram ao Vice-Presidente da República, Hamilton Mourão, Presidente do Conselho da Amazônia, uma proposta inédita de:

a) trabalhar junto com o Governo, sublinhando que só ele detém o poder de polícia;

b) oferecer linhas de crédito para agricultura e outras atividades, com juros subsidiados;

c) auxiliar, através de suporte de grupos jurídicos altamente especializados, na regularização fundiária da região;

d) estimular a bioeconomia, exemplificando com a possibilidade de processar o açaí em Manaus e exportar para outros países, revertendo a prática atual de enviar o fruto ao exterior, onde ele é industrializado;

e) não financiar mais empresas de carne que desmatarem a região, com isto desestimulando tal prática.

Em plena harmonia com esta nova forma de tratar do assunto, o Banco Central do Brasil lançou dia 8 de setembro passado a chamada Agenda BC\#, prevendo ações de sustentabilidade ambiental que incluem "uma linha financeira de liquidez sustentável e a inclusão de critérios de sustentabilidade para a seleção de contrapartes na gestão das reservas internacionais da instituição e para a seleção de investimento" (BC SUSTENTABILIDADE, 2020). 
Assim, os estímulos até hoje têm sido tímidos, seja por parte do Poder Público (v.g., com o Projeto Bolsa Verde, criado pela Lei $\mathrm{n}^{\circ}$ 12.512, de 14 de outubro de 2011 e regulamentado pelo Decreto $\mathrm{n}^{\mathbf{0}} 7.572 / 2011$ ), seja por iniciativa do capital particular. $\mathrm{Na}$ verdade, no âmbito privado eles podem ser fortalecidos por projetos com recursos do exterior, como o Conserv, incrementado com verbas da Noruega e Holanda (GIRARDI, Giovana, 2020, p. A18) ou mesmo do Brasil.

Em entrevistas ao jornal Estado de São Paulo, os presidentes do Itaú Unibanco e do BRADESCO declararam, respectivamente, que o Banco não financiaria empresas de carne que desmatassem irregularmente (SCHELLER; SCARAMUZZO, 2020, p. B7) e seriam dados subsídios para o produtor não tirar madeira (SILVA; GIRARDI, 2020, p. B1).

Tais iniciativas, sem dúvida alguma, representam uma inédita mudança de rumos no mundo empresarial e podem, sim, dar nova direção à política ambiental brasileira. Na verdade elas se adequam à proposta que inclui a prática do ESG, sigla em inglês que significa Environmental, Social and Governance, O ESG foi criado como uma métrica para avaliar o desempenho das empresas nesta nova conjuntura, ou seja, os financiamentos e subsídios passarão por uma contagem de diversos itens que avaliem os procedimentos das empresas.

No âmbito de grandes empresas de capital aberto, isto já é uma realidade. O Índice de Sustentabilidade Empresarial (ISE), criado em 2005, permite ao investidor direcionar seus recursos às que se acham em boa posição na avaliação ou, alternativamente, procurar um fundo de investimentos que tenha esta orientação.

Na verdade, as companhias precisarão mostrar que são sustentáveis ecológica, social e economicamente, pois “a adoção de uma agenda ESG traz diversos impactos positivos para uma empresa, como vantagens competitivas, melhora de reputação, maior lucratividade e até um aumento do seu valor a longo prazo" (LASCO, 2020, p. B6).

Isto implica, entre outras coisas, em um enorme aumento de empregos para antigas profissões, porém agora com especialização ambiental, nas áreas de física, engenharia, geografia, economia, administração, direito, química, engenharia ambiental, arquitetura e urbanismo, biologia e psicologia ambiental (JAKITAS, 2020, p. B10).

É verdade que no Brasil o grande motivo destas mudanças é a preocupação internacional com a Amazônia, que representa $60 \%$ do território brasileiro. Nesta região, uma grande quantidade de startups oferecem serviços ligados à bioeconomia, visando incrementar a economia com produtos locais, como os óleos extraídos de plantas da região, com os quais se 
produzem cosméticos, com grande mercado na Europa, Estados Unidos e Emirados Árabes (SILVA; GIRARDI, 2020, p. B1).

Todavia, as possibilidades de estímulos à sustentabilidade se estenderão a todo o território nacional. Neste panorama, o Brasil é considerado um país com grandes possibilidades para novas empresas com características consideradas ambientalmente amigas, as chamadas cleantechs. Assim, "entre as principais áreas de atuação das startups verdes estão energia limpa, transporte, agricultura e água" (GAVRAS; BRONZATI, 2010, p. B10).

As empresas que não se ajustarem aos novos tempos arcarão com as consequências de sua opção, certamente sofrendo suspensão de financiamentos, boicote na compra de seus produtos, seja no Brasil, seja no exterior, através de importadores.

\section{CONCLUSÕES}

Diante do exposto, é possível concluir que a forma das empresas tratarem com as questões ambientais, o respeito ético e legal que lhes é cobrado, impõe mudança radical. $\mathrm{O}$ lucro a qualquer custo não é mais aceito pela comunidade internacional nem pela população, em especial as novas gerações.

Nesta nova fase da evolução humana, sobre a pressão de organismos internacionais, como a Organização das Nações Unidas - ONU, as emendas tendem a amoldar-se aos novos tempos, criando setores de compliance para orientá-las nas melhores regras de conduta.

No entanto, sendo inafastável o objetivo de lucro que as caracteriza, torna-se indispensável que elas recebam incentivos econômicos para que a adesão seja perfeita. Atualmente, estes estímulos começam a tornar-se realidade, permitindo que se tenha uma visão otimista do futuro nesta área.

Por outro lado, aos que insistirem em manter-se com as práticas do passado, onde o desenvolvimento era a meta única e exclusiva, prevê-se dificuldades decorrentes não apenas das agências ambientais como também da censura dos consumidores.

Confiantes, devemos não apenas aguardar, mas também lutar por dias melhores. 


\section{REFERÊNCIAS}

BC Sustentabilidade. Banco Central lança agenda de sustentabilidade. Disponível em: https://climainfo.org.br/2020/09/10/banco-central-lanca-agenda-de-

sustentabilidade/\#: :text=A\%20chamada\%20Agenda\%20BC\%23\%20prev\%C3\%AA,do\%20papel\%2 0apenas\%20em\%202022. Acesso em: 19 out.2020.

BECKER, Michel. Perspectivas de mercado para madeira certificada. In: Revista da Madeira. Institut für Forstpolitik Arbeitsbereich Markt und Marketing Bertoldstr. Freiburg/AlemanhaMaio/2003 Disponível

em: http://www.remade.com.br/br/revistadamadeira_materia.php?num=296\&subject=Certifica\%E7\%E3o $\&$ title=Perspectivas $\% 20 \mathrm{de} \% 20$ mercado\%20para\%20madeira\%20certificada. Acesso em: 19 out.2020.

BRASIL. STF, Medida Cautelar apresentada em Ação Direta Inconstitucionalidade: ADI-MC 3540-DF, Tribunal Pleno, relator ministro Celso de Mello, j. $1^{\circ}$ set. 2005, DJ 03-02-2006 pp00014 ement. vol. 02219-03 pp-00528.

CARSON, Rachel. Primavera Silenciosa. São Paulo: Gaia, 2010.

GAVRAS, Douglas; BRONZATI, Aline. Com modelo que une sustentabilidade e inovação, cleantechs avançam no País. Jornal O Estado de São Paulo, Caderno Economia, 04/09/2020.

GIRARDI, Giovana. Projeto pagará por áreas preservadas. Jornal O Estado de São Paulo, Caderno Metrópole, 07/10/2020.

GOMES, Fábio Bellote. Manual de Direito Comercial. 2. ed. Barueri: Manole, 2007.

JAKITAS, Renato. Pesquisa indica os profissionais requisitados pela economia verde. Jornal $O$ Estado de São Paulo, Caderno Economia, 03/09/2020.

LASCO, Thiago. Quando investir bem dá resultado. Jornal O Estado de São Paulo, Caderno Economia,17/08/2020.

LIMA, Camila Cardoso; HORÁCIO, Lincoln Rafael. Responsabilidade social empresarial: instrumentos de gestão para a sustentabilidade. Disponível em: <http://conpedi.danilolr.info/publicacoes/02q8agmu/mwkmtp48/Ih1TcMxwblp7gGkh.pdf >, p. 20. Acesso em: 20 out. 2020.

MACHADO, Paulo Affonso Leme. Direito Ambiental brasileiro. 24. ed. São Paulo: Malheiros, 2014.

MEIRELES, Leandro. Manifesto de Davos quer capitalismo consciente. Disponível em: <https://www.consumidormoderno.com.br/2019/12/16/manifesto-davos-capitalismo-consciente/ $>$. Acesso em: 15 out. 2020.

NAÇÕES UNIDAS BRASIL. Objetivos de desenvolvimento sustentável. Disponível em: https://brasil.un.org/pt-br/sdgs. Acesso em: 12 out. 2020.

ODUM, Eugene P. Fundamentos de ecologia. Trad. de António Manuel de Azevedo Gomes. 4. ed. Lisboa: Fundação Calouste Gulbenkian, 1988.

PACTO GLOBAL. Disponível em: <www.pactoglobal.org.br/10-principios>. Acesso em: 20 out. 2020. 
POZZOLI, Lafayette, TOLEDO, Iara Rodrigues de. Análise do princípio constitucional da dignidade humana face a dimensão da afetividade e o direito fraternal. In: Problemata, v. 8. n. 1. João Pessoa: UFPB. 2017.

REQUIÃO, Rubens. Curso de Direito Comercial. 5. ed. São Paulo: Saraiva, 1975.

SAYEG, Ricardo. BALERA, Wagner. O Capitalismo Humanista. São Paulo: KBR Editora Digital Ltda., 2011.

SCHELLER, Fernando; SCARAMUZZO, Mônica. Não financiaremos empresas de carne que desmatarem. Jornal O Estado de São Paulo, Caderno Economia, 12/08/2020.

SILVA, Cleide; GIRARDI, Giovana. Baseadas em ativos da floresta, startups da Amazônia impulsionam a bioeconomia. Jornal O Estado de São Paulo, Caderno Economia, 23/08/2020.

SILVA JUNIOR, Altamiro. Fundos que administram US\$16,2 trilhões lançam manifesto em defesa da Amazônia. Disponível em: <https://sustentabilidade.estadao.com.br/noticias/geral,fundos-queadministram-us-16-2-trilhoes-lancam-manifesto-em-defesa-da-amazonia,70003015654>. Acesso em 15 out. 2020.

USERA, Raúl Canosa. Constituición y medio ambiente. Lima: Jurista, 2004.

VALOR ECONÔMICO. Brasil ignora pressão externa contra destruição ambiental. Rio de Janeiro: $10 / 10 / 2020$. 